\title{
High strain rate compression behaviour of 3D printed Carbon-PA
}

\author{
Mattia Utzeri ${ }^{1, a)}\left(\mathbb{D}\right.$, Emanuele Farotti ${ }^{1}$, Mattia Coccia ${ }^{1}$, Edoardo Mancini ${ }^{2}$, Marco Sasso $^{1}$ \\ ${ }^{1}$ Università Politecnica delle Marche-DIISM, Via Brecce Bianche, 60121 Ancona, Italy \\ ${ }^{2}$ Università degli Studi dell'Aquila-DIIIE Piazzale Ernesto Pontieri, 67100 L'Aquila, Italy \\ a) Address all correspondence to this author. e-mail: m.utzeri@pm.univpm.it
}

Received: 16 December 2020; accepted: 15 May 2021, published online: 27 May 2021

In the last few years, Fused Filament Fabrication is growing in the industrial field for the manufacture of final products by using new materials with high mechanical performances. Among those, one of the strongest is Carbon-PA. This is a composite material made by Nylon thermoplastic matrix filled with short carbon fibers reinforces. The aim of this work is to investigate its mechanical properties in static and dynamic conditions. Cylindrical specimens were produced by extruding the material in the three main printing directions. Then, uniaxial quasi-static and dynamic compression tests have been performed to evaluate its strain rate sensitivity. Dynamic tests have been carried out through a direct Split Hopkinson Bar setup with a pulse-shaping technique. The results show a compression behaviour dependent on the printing direction and strain rate. The behaviour of Carbon-PA was different between static and dynamic condition, passing from ductile to brittle. Moreover, a tomography analysis was carried out on the samples to evaluate the voids distribution.

\section{Introduction}

According to ISO/ASTM 52900 standard, the Material Extrusion $(\mathrm{ME})$ is one of the numerous additive manufacturing (AM) processes, in which material is selectively dispensed through a nozzle or orifice. Material Extrusion technology for polymers is known as Fused Filament Fabrication (FFF), also known under the trademarked term Fused Deposition Modeling (FDM), and is one of the most popular processes for prototyping applications [1]. Fused Deposition Modeling consists of printing a continuous filament of a thermoplastic material, according to a filling pattern, or strategy, thus to obtain the desired shape. The filament is fed from a coil and melted by means of a heated head. The molten material is forced out of the extruder's nozzle and is deposited over the printing platform. Once the first layer is completed, the second layer can then be directly deposited onto the growing work-piece until the object's fabrication is complete.

In principle, almost any of thermoplastic polymers can be 3D printed with Fused Filament Fabrication, such as Acrylonitrile Butadiene Styrene (ABS), Polycarbonate (PC), Polylactide (PLA), Polyamide (PA), Polyether Ether Ketone (PEEK), Polyetherimide (PEI), Polyethylene Terephthalate Glycol-modified (PETG), etc. Nevertheless, their mechanical proprieties are too low for using them in industrial applications [2]. Therefore, in recent years new FFF materials with high mechanical performances are being developed [3]. In order to increase material performances, reinforces are extruded along with thermoplastic filament. These can be in the form of short or long fibers, nanotubes, powders and fillers $[4,5]$. Among them, the most popular are Carbon-PEEK, i.e. short carbon fiber reinforces and PEEK thermoplastic matrix, Carbon-PLA, Glass-PA, and Carbon-PA. Hence, it is really important to find out their mechanical behaviour to understand their potential in industrial applications. The knowledge of their mechanical properties can lead to innovative design solutions merging the additive manufacturing advantages and the materials dynamic performances for transport, and aerospace applications, such as impact attenuators, lattice absorption structures, and so on.

Focusing on carbon fiber reinforced materials, several works concerning the mechanical characterization can be found in the literature. For example, Ning et al. [6] analysed the effects of fiber content for Carbon-ABS on the tensile and flexural properties (such as Young modulus, toughness, yield strength, and ductility). Moreover, Somireddy et al. [7] investigated the mechanical properties of Carbon-ABS in relation to material deposition strategy. 
Studies on Carbon-PLA and Carbon-PC can be found in the works of Ferreira et al. and Gupta et al. [8, 9]. Blok et al. [10] compared the tensile properties between short and continuous fiber reinforced Carbon-PA. Furthermore, AM parts are characterized by in-plane anisotropy. In FFF, the molten thermoplastic filament is deposited lane by lane in given directions, forming a layer, then layer on layer; as a result, AM parts are likely to show anysotropic behaviour, as pointed out by many authors [11-13]. In addition, flawed infill of the slices can occur, as shown by Spoerk et al. [14], who investigated the mechanical anisotropy in Carbon-PP manufactured by FFF, and by Bhandari et al. [15], who highlighted the orthotropic nature and inter-layer mechanical strength of CarbonPETG and Carbon-PLA.

The investigation of dynamic properties of FFF materials is poor in the literature, in particular for reinforced ones. For instance, Verbeeten et al. [16] studied the anisotropy and ratedependence of poly(lactic-acid) produced by Material Extrusion Additive Manufacturing. Their results showed semi-ductile behavior under moderate dynamic conditions. In Casavola et al. [17] the analysis of the mechanical behavior of FFF ABS under impact tensile loading has been shown. However, in both studies a maximum strain rate of about $1 \mathrm{~s}^{-1}$ was reached.

This study focuses on the mechanical characterization of a Carbon-PA composite, fabricated by Fused Filament Fabrication, subjected to quasi-static and high strain rate compression loading. The influence of printing direction has been also investigated in order to asses the effect of infill direction. The experimental section provides an extensive description of specimen fabrication and test methods. The extrusion parameters and strategies are described, as well as the compressions both in quasi-static conditions by an electro-mechanical machine and in dynamic one by means of a Hopkinson bar system. Then, the results section analyzes the mechanical behavior of the material in terms of strain rate sensitivity and deposition strategy.

The causes of the different mechanical response in relation to the direction of extrusion have also been investigated in terms of the porosity of printed specimens. Therefore, a tomography analysis has been carried out on the samples in each direction to evaluate the distribution of voids. The porosities inside the samples have been computed through image analysis technique which is widely exploited on the field of experimental mechanics [18-20]. Finally, a discussion on the failure modes has also been presented following tests findings and tomography investigations.

\section{Results and discussions}

\section{Quasi-static behaviour}

Specimens subjected to quasi-static compression test showed ductile behavior. Therefore, the test results were limited up to $100 \%$ of negative true strain. Figure 1 shows the true stress-true strain compression curves of each specimen type. It can be noted that the material response assumes a different trend according to the printing direction. After an initial linear elastic part, both $\mathrm{L}$ and $\mathrm{T}$ specimen's curves have a local peak (points $\mathrm{a}, \mathrm{b}$ ) before the stress decreases. Their trend is similar but occurs at different stress levels. On the contrary, the curve of V specimen doesn't show the local maximum at the beginning of plastic region, and follows a strain hardening behaviour (point c).

The different aspect of the curves can be related to the deposition strategy. Indeed, the V specimens consist of an overlapping of slices which are normal to the applied load. Conversely, $\mathrm{T}$ and $\mathrm{L}$ specimens are built with the layers aligned with the load direction, but oriented $90^{\circ}$ relative to each other.

The static compression properties of three specimens for each printing direction are reported in Table 1.The Young's modulus is similar for each printing direction and hence it doesn't depend on the deposition strategy. The yield stress for $\mathrm{L}$ and $\mathrm{T}$ specimens has been considered as the first local peak (points a,b of Fig. 1). On the other hand, the yield stress for V specimens has been determined as $R p_{0.2 \%}$, analogously with metals. It can be affirmed that the $\mathrm{L}$ specimens are the strongest, followed by the $\mathrm{V}$ and $\mathrm{T}$ ones. The resistance of the material is thereby dependent on the deposition strategy. In details, the compression strength is the highest when the fuse is deposited accordingly to the load direction (L specimens), as shown in Fig. $2 \mathrm{~b}$.

As regards the $\mathrm{V}$ and $\mathrm{T}$ specimens, the point is more elaborate. Specimens $\mathrm{V}$ and $\mathrm{T}$ have a quite similar longitudinal section. In fact, the vertical sections in Fig. 2a show how these specimens are formed by a series of filaments perfectly stacked one over each other. However, in terms of the extrusion process, their cohesion is necessarily different. The V specimens consist of a series of horizontally bound layers overlapping one over each other and perpendicular to the load direction.

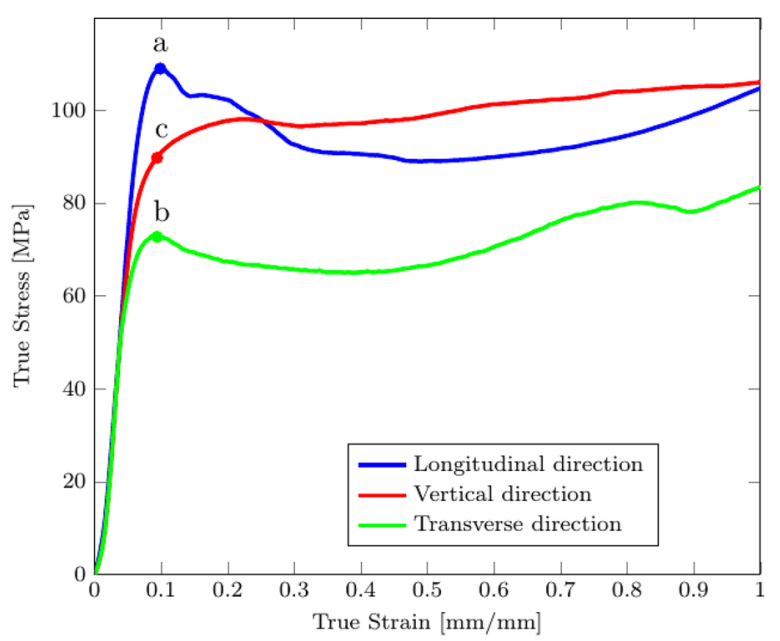

Figure 1: Quasi-static compression results. 
TABLE 1: Quasi-static mechanical properties (average value \pm standard deviation).

\begin{tabular}{lcccc}
\hline \hline & \multicolumn{3}{c}{ Material deposition strategy } & \\
\cline { 2 - 4 } Mechanical properties & Longitudinal direction & Vertical direction & Transverse direction & Unit \\
\hline Young modulus & $1827 \pm 84$ & $1809 \pm 57$ & $1796 \pm 61$ & $\mathrm{MPa}$ \\
Yield stress & $109.04 \pm 0.55$ & $91.05 \pm 0.32$ & $72.83 \pm 1.02$ & $\mathrm{MPa}$ \\
\hline \hline
\end{tabular}

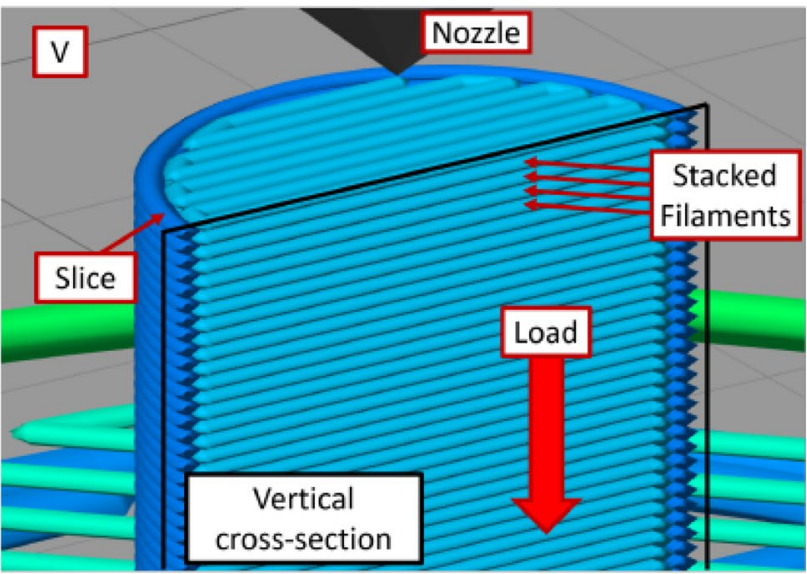

(a) Vertical direction

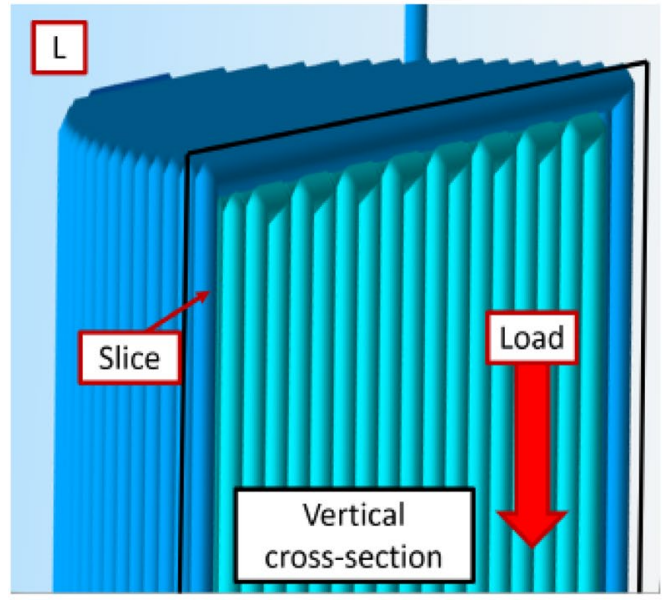

(b) Longitudinal direction

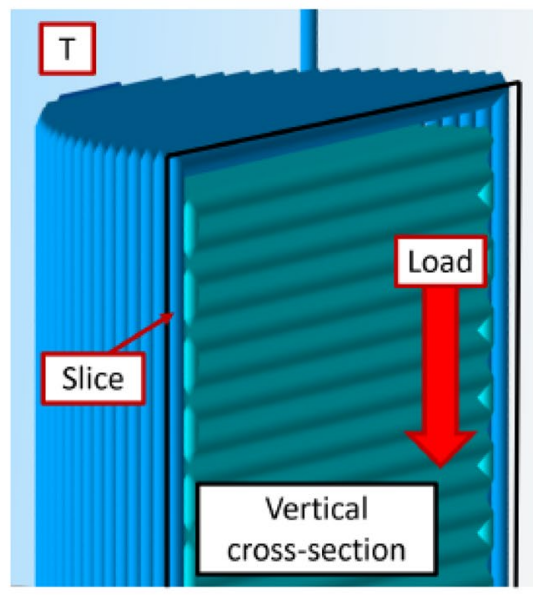

(c) Transverse direction

Figure 2: Filaments arrangement in verticals cross-sections.

Conversely, the $\mathrm{T}$ specimens have the bound layers arranged vertically in accordance with the load direction, Fig. 2c. The different printing sequence between the $\mathrm{V}$ and $\mathrm{T}$ samples determines differences both in terms of polymer cooling and filling in-homogeneity related to the process (height of layer, infill pattern, outer shell). This determines a lower adhesion between the single layers than the cohesion between the filaments of the same layer. For these reasons, the resistant section of $\mathrm{T}$ specimens (with respect to the compression load) is made up of a set of filaments not belonging to the same layer and is therefore more compliant. The layers of $\mathrm{L}$ specimens show the same criticality of $\mathrm{T}$ specimens regarding the load direction, with a similar shape of stress-strain curve. However, the filament arrangement is parallel to the load and increases the strength significantly.

After the compression test, specimens didn't maintain a cylindrical shape, as shown in Fig. 3. The V and $\mathrm{T}$ specimens increased their dimensions along a preferential direction. In order to correlate the deformation directions with the deposition strategy (Fig. 3b and c) double-axis reference system was drawn on the deformed and undeformed specimens. The red direction 
is aligned with the extruded filament whereas the yellow axis is normal to the red one. Both $\mathrm{V}$ and $\mathrm{T}$ specimens showed an ultimate shape with a plastic flow along the yellow axis, meaning that the plastic flow found a strong opposition along the direction of the extruded filaments. It can be assessed that the deposition strategy has also an influence on the anisotropic and plastic behaviour.

\section{Dynamic behaviour}

The dynamic compression tests performed on each type of specimen revealed a brittle behaviour of the material, in opposition to what observed in the quasi-static tests. The results prove a strain rate sensitivity of Carbon-PA, as the mechanical properties change with the strain rate. In all tests, the compression strength is higher than the static condition. However, the increase in strength is different for each type of specimen. Figure 4 shows the true stress-true strain curves in dynamic and static condition of the Longitudinal, Transverse, and Vertical specimens, respectively. The curves were reported separately to highlight the differences in mechanical properties among the specimens with the same deposition strategy. Thanks to the pulse shaping technique, the strain rates were quite constant during the tests.

The Vertical specimens are more sensible with strain rate than the other two configurations. Their maximum compression strength reaches $168.7 \mathrm{MPa}$ at $517 \mathrm{~s}^{-1}$ corresponding to an increment of about $86.8 \%$. Conversely, the Transverse and Longitudinal specimens increase their maximum strength up to $64.8 \%$ and $46.7 \%$ approximately at the same strain rate, respectively. As regards the Young's modulus, the trend is similar. In fact, for Longitudinal specimens it reaches $3217 \mathrm{MPa}$ corresponding to an increment of $76.1 \%$. On the contrary, the measured stiffness of Transverse and Vertical specimens is $2002 \mathrm{MPa}$ and $1988 \mathrm{MPa}$, corresponding to an increment of $11.3 \%$ and $9.7 \%$, respectively.

By analyzing the trend of the true stress-true strain curves, a difference in the ductile-to-brittle transition can be noted. Passing from quasi-static to dynamic condition, the reduction of ultimate strain for the $\mathrm{V}$ curves is quite gradual as the strain rate increases, contrarily to the sharp transition observed in the $\mathrm{L}$ and $\mathrm{T}$ ones.

The L specimens show an unusual behaviour. In fact, although the strain to failure trend is generally decreasing with the strain rate, there is a premature failure of the specimen above a certain rate, resulting in a lowering of the maximum measured stress. In the L1 and L2 curves of Fig. 5c the ultimate strain is strongly reduced and the failure occurs at lower stress levels. The ultimate stress drops dramatically from $165 \mathrm{MPa}$ of L3 curve to $140 \mathrm{MPa}$ of L1 curve, with a strain rate increment of around $300 \mathrm{~s}^{-1}$.

The strain rate dependence of mechanical properties of these materials in terms of strength and failure strain are presented in Fig. 5b. Here it can be observed as the resistance typically increases roughly linear with strain rate in a semi-logarithmic graph. As mentioned before, the L specimens exhibit a nonmonotonous behavior due to premature failure during compression over a certain level of strain rate. Further, as far as the strain to failure is concerned, it is possible to identify a decreasing trend with strain rate for all the specimens, denoting an increasing brittleness of the material.
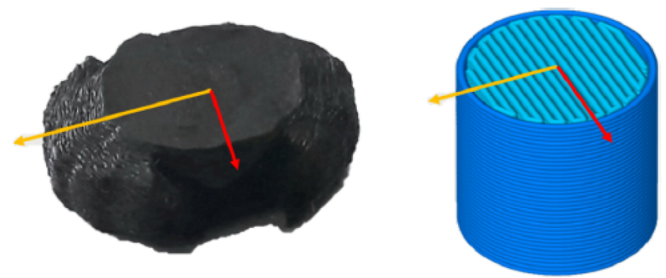

(a) Vertical direction
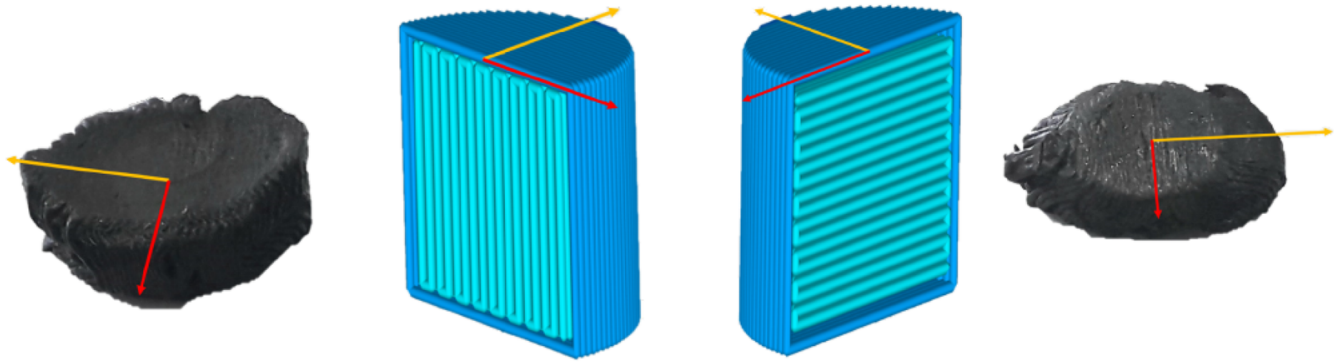

(b) Longitudinal direction

(c) Transverse direction

Figure 3: Specimen after quasi-static compression test. 


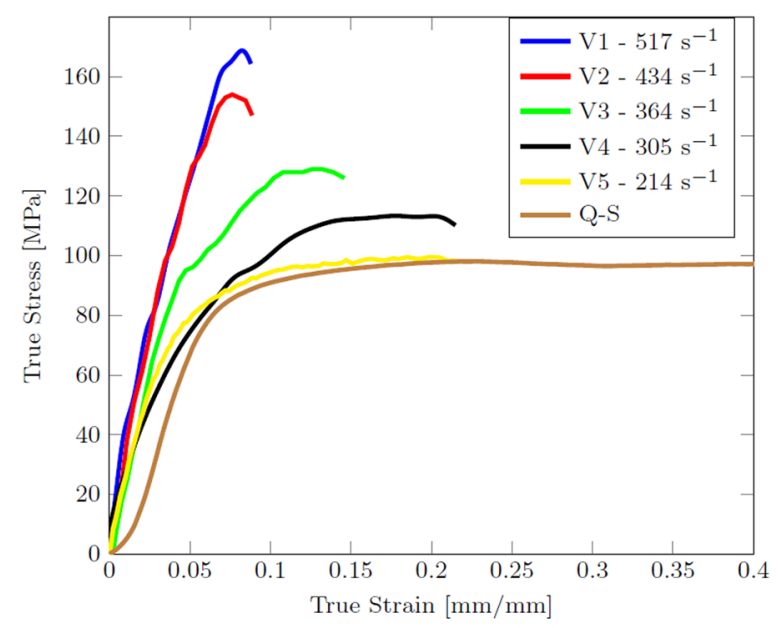

(a) Vertical direction

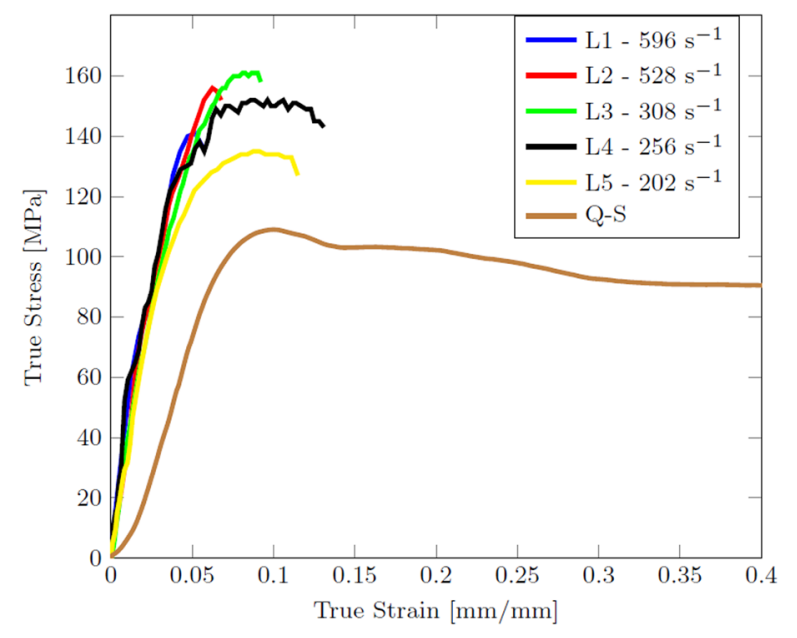

(b) Longitudinal direction

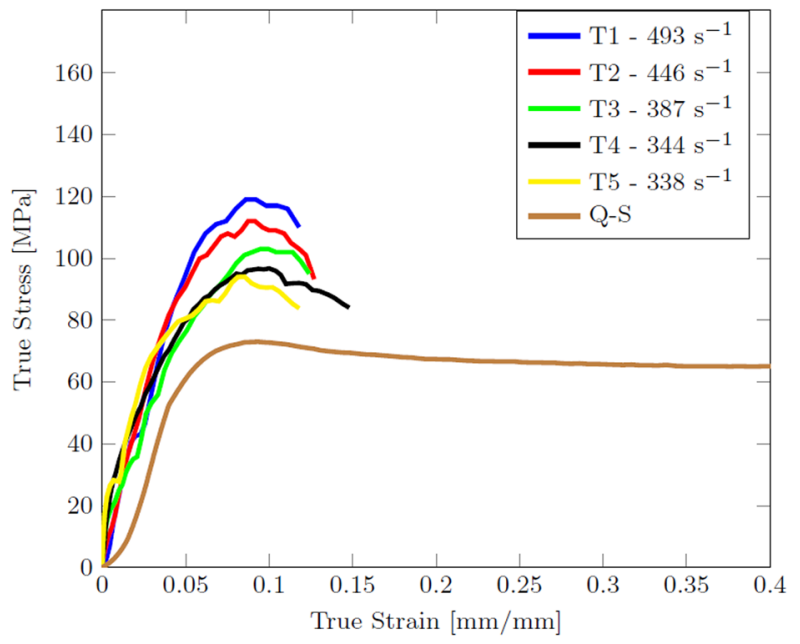

(c) Transverse direction

Figure 4: Dynamic compression results.

All type of specimens showed the same failure mode in dynamic condition. The samples broke perfectly in two half-cylinder as shown in Fig. 6 and supplementary animations (Online Resource 1, 2, and 3). Only the V specimens showed a pull-out failure at the external lateral surface of the cylinders. This type of failure is unavoidable because of the presence of the extruded filaments of the outer shell crossing the vertical plane of fracture.

Similarly to "Quasi-static behaviuor" section, double-axis reference system was drawn on the broken and undeformed specimens. The red direction is aligned with the extruded filament whereas the yellow axis is normal to the red one. For both $\mathrm{L}$ and $\mathrm{T}$ specimens, the vertical fracture plane corresponds to one of the central deposition planes. On the contrary, for the $\mathrm{V}$ specimens the fracture plane is the one where the filaments of each slice were stacked. As described in the previous section, L specimens have the filaments arranged according to the load direction and this should lead to the best deposition strategy in terms of mechanical strength. However, as evidenced by the experimental results of Fig. 5 a sudden drop in performance is observed once a certain strain rate level is exceeded, both in terms of resistance and strain to failure.

A possible explanation can be associated to the strain rate sensitivity of the polymer matrix, together with the specimen structure provided by the printing process. According to what discussed in "Quasi-static behaviuor" section, the deposition strategy for L specimens determines an overlapping of layers arranged parallel to the load direction, whose connection is weaker than the bond formed between the filaments of the single layer. Therefore, the specimen rupture occurs primarily along the connection region between the layers. As the strain rate increases, the matrix becomes too brittle, thus triggering a fracture along the separation plane of the layers. 


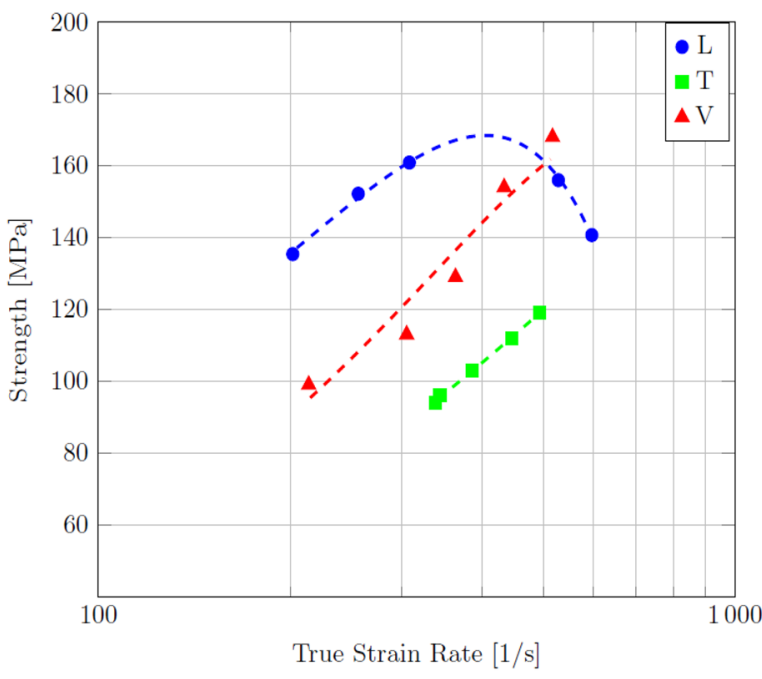

(a) Influece of the strain rate on the mechanical

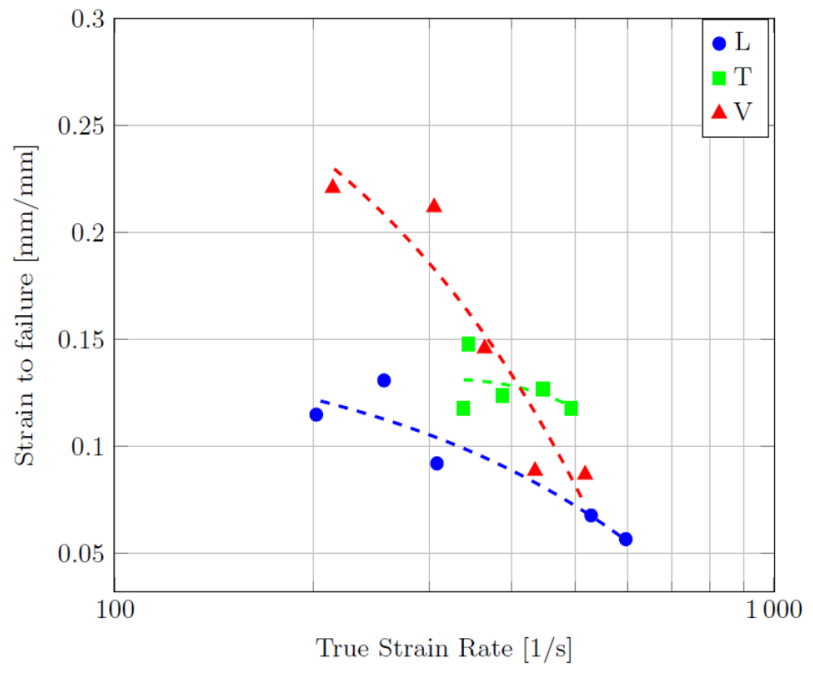

(b) Influence of strain rate on the strain to failure strength.

Figure 5: Strain rate dependence on mechanical properties.
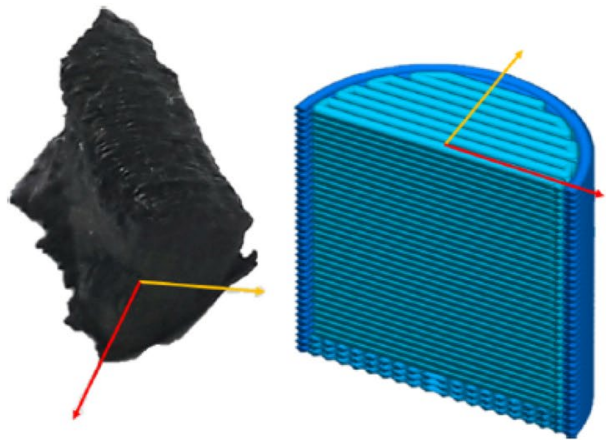

(a) Vertical direction
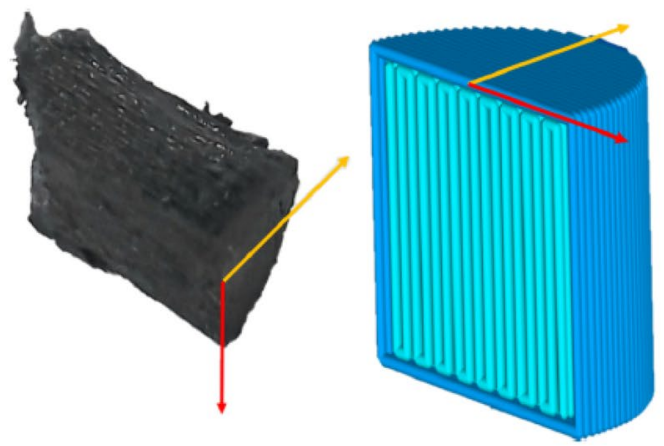

(b) Longitudinal direction
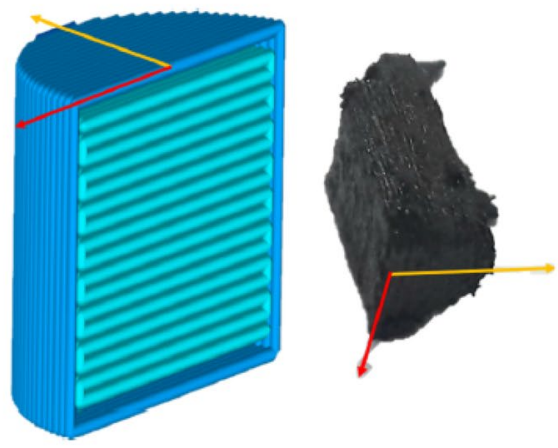

(c) Transverse direction

Figure 6: Specimen after Dynamic compression test.

The deposition strategy for $\mathrm{T}$ specimens is quite similar to that of $\mathrm{L}$ ones, as well as the fracture mode along the printing planes under dynamic loading. However, the different deposition direction results in lower mechanical strength because each layer is more flexible than that of $\mathrm{L}$ specimens. In addition, it allows the material to keep up a more ductile behaviour also at 
high strain rates, without incurring premature structural failure. Finally, regarding the $\mathrm{V}$ specimens, the fracture mode is influenced by the deposition strategy. In fact, the failure arises along the discontinuities between the filaments stacked one over each other. This also determines a preferential rupture plane, as in the case of $\mathrm{L}$ and $\mathrm{T}$ specimens. From a mechanical point of view, it is noted that $\mathrm{V}$ specimens tend to withstand dynamic loads better than L specimens. In fact, a limit strain rate value causing a sudden loss of performance has not been identified in the $\mathrm{V}$ specimens in the investigated range; furthermore, the maximum resistance measured for $\mathrm{V}$ specimen is similar to that of $\mathrm{L}$ specimen. The ductility of $\mathrm{V}$ specimens is higher than $\mathrm{L}$ because of the greater cohesion between the filaments of the layers in relation to the loading direction, as described in the previous section.

\section{Tomography analysis}

The tomography analysis reveals the average voids percentage almost uniform for all type of samples. The vertical samples have an average porosity about $1.7091 \%$, whereas the longitudinal and transverse samples have a slightly greater porosity of $1.8902 \%$ and $1.8450 \%$ respectively. Hence, it can be affirmed that the printing direction has no significant influence on the degree of porosity of the specimens. Moreover, the voids distribution is not homogeneous along the scan plane and the scan directions, as shown in Fig. 7a and b, respectively. The latter figure shows the porosity trends in the vertical sample, according to different scanning directions. The red line of Fig. $7 \mathrm{~b}$ represents the voids percentage at each XY Plane (Plane Red on the cylinder) perpendicular to the printing direction $(\mathrm{Z}+)$. On the contrary, the blue and green line represent the voids percentage in other scanning directions parallel to the platform.

An analysis of the trends of the curves in Fig. $7 \mathrm{~b}$ shows that the scans in directions parallel to the platform provide quite similar and regular voids percentage values along the scanning direction. On the contrary the voids percentage along the direction perpendicular to the XY Plane show more oscillations. This result was analysed through the Fast Fourier Transform (FFT) tool. The FFT shows a relevant spatial frequency in the signal equal to 0.02631 /slice (the yellow point in Fig. 7c), corresponding to 38 voxels. By converting this measurement with the resolution of the tomograph scans, it results in a signal period corresponding to $0.410 \mathrm{~mm}$, corresponding to the height of each printed layer. The maximum porosity is therefore found at the stacking planes of the filaments (layers interfaces), while a minimum value is found in the centre of the layers.

The tomography analysis carried out in longitudinal and transverse specimens showed analogous behaviour of the voids percentage. The voids trend along directions parallel to the platform are similar and regular, while periodic oscillations are visible along the printing direction. These results confirm that the stacking of filaments in $\mathrm{Z}+$ direction during the FFF process creates severe discontinuity inside the specimens. Therefore, the cohesion between the printed slice, one above the other, can be lower than the other stacking direction.

\section{Conclusions}

In this study the compression behaviour of Carbon-PA fabricated by Fused Deposition Modelling was investigated by means of quasi-static and dynamic tests. In order to find out the mechanical properties of a $3 \mathrm{D}$ printing material, the tests were performed on three type of cylindrical sample made with different deposition strategy, named Longitudinal, Transverse, and Vertical.

The quasi-static compression results showed a ductile behaviour of the materials. The Longitudinal specimens turned out to be stronger than the other two type reaching $109 \mathrm{MPa}$ of maximum stress. The strain-stress curves of the Transverse and Longitudinal specimens have a similar trend, because of their similar deposition strategy. On the contrary, for the Vertical specimens the trend is opposite, and has a strain hardening behaviour in the plastic region. The differences in the experimental curves and plastic flow have been discussed on the basis of the deposition strategy.

The dynamic compression results showed a brittle behaviour of the materials. The Vertical specimens turned out to be stronger than the other two types, reaching 168.7 MPa of maximum stress, corresponding to an increase of about $86.8 \%$. Moreover, a limit value of material resistance with increasing strain rate has been found for Longitudinal specimens. The other specimen types showed a monotonic increasing resistance behaviour with strain rate.

Furthermore, the analysis of the fracture modes reveals that the specimens failure can occur because of the different cohesion of the filaments between layers. In fact, the rupture can occur between the layers, as the cases of Transverse and Longitudinal specimens. On the other hand, the failure can occur along the planes where the filaments were stacked by different slices, as the case of Vertical specimens.

The tomography analysis confirms the stacking of filaments in $\mathrm{Z}+$ direction during the FFF process and creates severe discontinuity inside the specimens. Therefore, the cohesion between the printed slice, one above the other, can be lower than the other stacking direction. Consequently, in the quasi-static tests the deposition strategies are the most relevant charaterisic to determine the mechanical properties and the voids distribution can be ineglected. However, in dynamic test the brittle beahviour of Carbon-PA together with the porosity distribution can lead to a premature failure along to the intarface between the printed slices. 
(a)
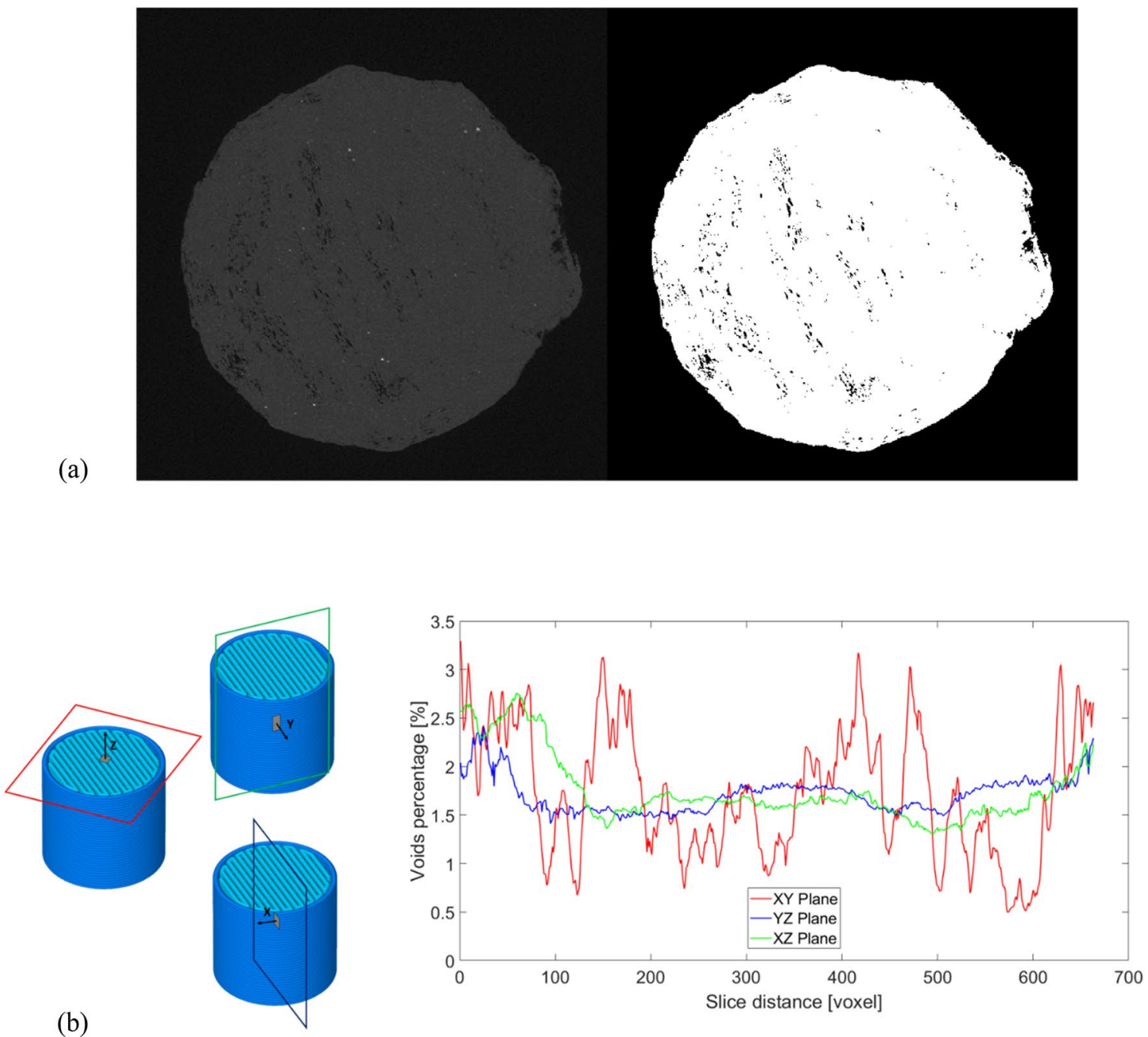

(b)

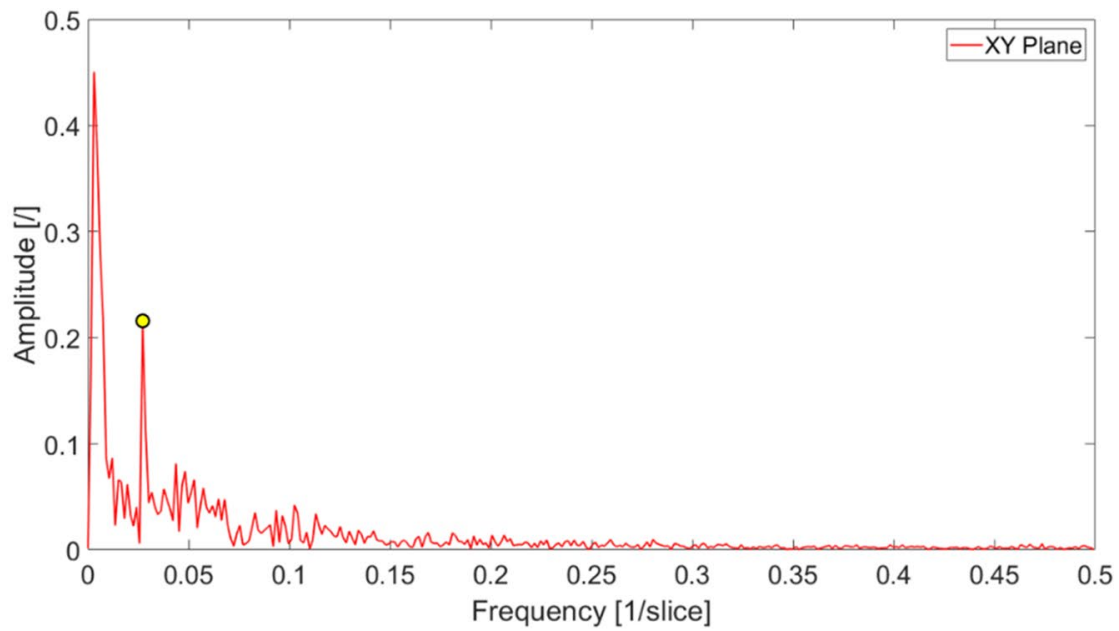

Figure 7: Tomography analysis: (a) Slice obtained through the tomography and its binarization; (b) Voids percentage trends computed along to $\mathrm{X}, \mathrm{Y}$ and Z directions; (c) Fast Fourier Transform (FFT) of XY-Plane signal. 


\section{Materials and methods}

\section{Specimens fabrication}

The material used is a commercial Carbon-PA supplied by Roboze $\odot$, in coil form suitable for FFF 3D printing. Roboze's Carbon-PA is a thermoplastic composite filament which is composed by PA6.6 matrix and short carbon fibers reinforcement ( $20 \%$ in weight). Carbon-PA samples were fabricated by means of Roboze@ ONE $400+3$ D printer.

According to Roboze $($ specifications, the coil was preheated at $120^{\circ} \mathrm{C}$ for $4 \mathrm{~h}$ before printing and kept at $70{ }^{\circ} \mathrm{C}$ during the deposition. All the other printing parameters (reported in Table 2), such as infill, raster angle, layer height and outer shells, were set to be the best suitable for the material. The infill pattern and angle were kept the same for all printed layers. No post-treatments were performed on the specimens.

Cylindrical samples were printed following three main directions, which match with the principal axis of the $3 \mathrm{D}$ printer; $\mathrm{X}$ and $\mathrm{Y}$ axis determined the building printer plane (or BED) while the $\mathrm{Z}$ direction was the layers increment direction. The cylindrical samples were grouped in Longitudinal, Transverse and Vertical, based on the deposition strategy: they were named L, T, V as in Fig. 8, respectively. This way of representation allows to easily identify the specimens with the infill direction.

The Vertical samples were printed with the circular face of the cylinder on the building platform. The infill and the deposition directions fitted with $\mathrm{X}$ axis and $\mathrm{Z}$ axis, respectively. On the other hand, the Transverse and Longitudinal samples were cylinder lied down on their side. The axis of the Longitudinal specimens has been oriented in the $\mathrm{X}$ direction, as well as the infill direction. The Transverse samples were aligned with the cylinder axis normal to the $\mathrm{X}$ direction. All process parameters and orientation were programmed by Simplify 3D slicing software.

Slenderness ratio of cylindrical samples was set $D_{0} / L_{0}=1$, where $D_{0}$ is the nominal sample diameter and $L_{0}$ is the height.

TABLE 2: Extrusion parameters.

\begin{tabular}{lll}
\hline \hline Parameter & Value & Unit \\
\hline Filament diameter & 1.75 & $\mathrm{~mm}$ \\
Nozzle diameter & 06 & $\mathrm{Mm}$ \\
Extrusion temperature & 240 & ${ }^{\circ} \mathrm{C}$ \\
Platform temperature & 45 & ${ }^{\circ} \mathrm{C}$ \\
Layer height & 0.2 & $\mathrm{~mm}$ \\
Infill & 100 & $\%$ \\
Extrusion speed & 3000 & $\mathrm{Mm} / \mathrm{min}$ \\
Infill pattern & Zig Zag & - \\
Infill angle (X axis) & L:0-V:0-T:0 & ${ }^{\circ}$ \\
Outer shell & 1 & - \\
Raft & 2 Layer-infill 40\% & - \\
Slicing software & Simplify 3D & - \\
\hline \hline
\end{tabular}

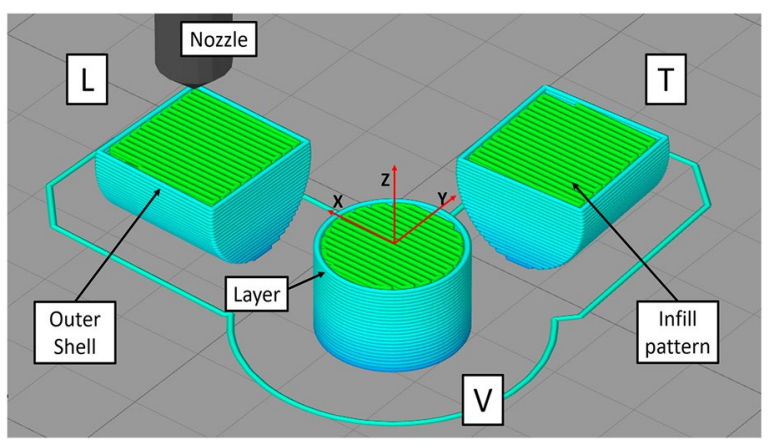

Figure 8: Material deposition strategy.

The length of the specimens was $L_{0}=8 \mathrm{~mm}$, in order to achieve the dynamic equilibrium during the Split Hopkinson Bar tests $[21,22]$.

\section{Tomography analysis}

Tomography analysis was carried out to evaluate the voids percentage inside the samples. The analysis was performed by means of Metrotom Tomography (ZEISS) with a voxel size of about $11 \mu \mathrm{m}$. The voids percentage was evaluated through image processing in MATLAB, as shown in Fig. 7a. Each image was binarized and the voids percentage was computed as follows:

Voids percentage or porosity $=\frac{\sum_{i} A_{\mathrm{S}}-\sum_{i} A_{\bar{S}}}{\sum_{i} A_{\mathrm{S}}} \times 100$

where $A_{\mathrm{S}}$ and $A_{\overline{\mathrm{S}}}$ are the area of printed surface and the area of non-porous surface for each slice $i$ of the tomography scans, respectively [18].

\section{Compression tests}

Static and dynamic compression tests were carried out in the laboratory of Università Politecnica delle Marche. Quasi-static compression tests were performed by means of standard electro-mechanical machine, Zwick/Roell@Z050, equipped with an extensometer. The forks were clamped on rigid cylindrical supports above and below the specimen because of its small dimensions. Molykote@MoS2 grease was put between the samples/cylinders interface to reduce as much as possible the friction effects during the test. Test speed was set to $0.05 \mathrm{~mm} / \mathrm{min}$; therefore, the strain rate was $1.04 \mathrm{e}^{-4} \mathrm{~s}^{-1}$.

Dynamic compression tests were performed by means of the direct Split Hopkinson Bar (SHB) [23-25]. The system consists of three aligned bars (Pre-stressed, Input and Output) of $18 \mathrm{~mm}$ in diameter and 3.0, 7.5, and $4.0 \mathrm{~m}$ long, respectively.

The Pre-stressed bar is firstly pretensioned by means of an electro-actuator at its end. The preload is suddenly released by the rupture of a sacrificial element. Hence, a compression wave is generated and travels along the bars. The length of the Input 
Bar is designed to measure the incident and reflected wave signals separately. Two strain gauge rosettes are placed on the Input and the Output bars to measure the strain waves. The Input wave is sampled at the middle of the bar while the Output one at a distance of $100 \mathrm{~mm}$ from the specimen position. Voltage signals are acquired by a 16-bit DAQ card (NIC PCI-6120) and then converted to strains. Further details of this SHB device and applications can be found in [23, 26-28].

The measurement of specimen's mechanical properties is derived by the processing the strain wave signals. When the input wave arrives to the bar-specimen interface it is partly transmitted through the output and partly reflected back into the input. By measuring the reflected and transmitted strain waves, here denoted as $\varepsilon_{\mathrm{R}}$ and $\varepsilon_{\mathrm{T}}$, it is possible to calculate the nominal strain rate $\dot{\varepsilon}$, strain $\varepsilon$, and stress $\sigma$ in the specimen, through the following equations [29]:

$\dot{\varepsilon}(t)=-\frac{2 C_{0}}{L_{\mathrm{S}}} \varepsilon_{\mathrm{R}}(t), \quad \varepsilon(t)=-\frac{2 C_{0}}{L_{S}} \int_{0}^{t} \varepsilon_{\mathrm{R}}(t) \mathrm{d} t, \quad \sigma(t)=\frac{A_{\mathrm{B}} E_{\mathrm{B}}}{A_{\mathrm{S}}} \varepsilon_{T}(t)$

where $A_{\mathrm{B}}$ and $E_{\mathrm{B}}$ are the cross-sectional area and Young modulus of the bars and $L_{S}$ and $A_{S}$ denote the specimen original gauge length and cross sectional area, respectively.

In this study, the Pre-stressed and Input bars were in 17-4 $\mathrm{PH}$ steel. On the contrary, the Output bar was in aluminium, in order to increase the measurement sensibility, which is necessary for low strength materials like polymers. As the quasi-static tests, Molykote $\odot \mathrm{MoS} 2$ grease was used to reduce the friction effects. Moreover, high speed camera (Photron@AS4) was used to record at $100 \mathrm{kHz}$ the side area of the samples during the compression tests. The shape of the generated wave in the Input bar is typically rectangular. However, for brittle materials, like reinforced polymers, this shape is not ideal [30]. For this reason, an aluminum dummy disc has been used as pulse shaper to improve the dynamic tests. In fact, a smoothed pulse contributes to reach the dynamic equilibrium and avoid premature fracture in low impedance brittle materials [31]; moreover, it allows to achieve nearly constant strain rate.

The presence of the pulse shaper makes the incident wave longer than normal, so that the length of the Input bar prevented incident and reflected signals from being measured separately. In this case, the reflected wave can not be directly measured from the strain gauge, but can be obtained using the incident and transmitted waves. Since the Output bar material was different from the Input one, the signal of the transmitted wave was corrected according to the different Young's modulus of the two bars, $E_{\mathrm{In}}$ and $E_{\mathrm{Out}}$, as in the following:

$$
\varepsilon_{\mathrm{R}}(t)=\varepsilon_{\mathrm{I}}(t)-\varepsilon_{\mathrm{T}}(t) \frac{E_{\mathrm{Out}}}{E_{\mathrm{In}}}
$$

\section{Data availlability}

The datasets generated during and/or analysed during the current study are available from the corresponding author on reasonable request.

\section{Funding}

Open access funding provided by Università Politecnica delle Marche within the CRUI-CARE Agreement.

\section{Declarations}

Conflict of interest On behalf of all authors, the corresponding author states that there is no conflict of interest.

\section{Supplementary Information}

The online version contains supplementary material available at https://doi.org/10.1557/s43578-021-00248-9.

\section{Open Access}

This article is licensed under a Creative Commons Attribution 4.0 International License, which permits use, sharing, adaptation, distribution and reproduction in any medium or format, as long as you give appropriate credit to the original author(s) and the source, provide a link to the Creative Commons licence, and indicate if changes were made. The images or other third party material in this article are included in the article's Creative Commons licence, unless indicated otherwise in a credit line to the material. If material is not included in the article's Creative Commons licence and your intended use is not permitted by statutory regulation or exceeds the permitted use, you will need to obtain permission directly from the copyright holder. To view a copy of this licence, visit http://creativecommons.org/licenses/by/4.0/.

\section{References}

1. F.M. Mwema, E.T. Akinlabi, Fused Deposition Modeling (Springer, Cham, 2020). https://doi.org/10.1007/ 978-3-030-48259-6_1

2. M. Srivastava, S. Rathee, S. Maheshwari, T.K. Kundra, Additive Manufacturing: Fundamentals and Advancements (CRC Press, Boca Raton, 2019). https://doi.org/10.1201/9781351049382

3. N. Guo, M.C. Leu, Front. Mech. Eng. (2013). https://doi.org/10. 1007/s11465-013-0248-8

4. A.D. Valino, J.R.C. Dizon, A.H. Espera Jr., Q. Chen, J. Messman, R.C. Advincula, Prog. Polym. Sci. (2019). https://doi.org/10. 1016/j.progpolymsci.2019.101162 
5. N. van de Werken, J. Hurley, P. Khanbolouki, A.N. Sarvestani, A.Y. Tamijani, M. Tehrani, Compos. Part B: Eng. (2019). https:// doi.org/10.1016/j.compositesb.2018.12.094

6. F. Ning, W. Cong, J. Qiu, J. Wei, S. Wang, Compos. Part B: Eng. (2015). https://doi.org/10.1016/j.compositesb.2015.06.013

7. M. Somireddy, C.V. Singh, A. Czekanski, Eng. Fail. Anal. (2020). https://doi.org/10.1016/j.engfailanal.2019.104232

8. R.T.L. Ferreira, I.C. Amatte, T.A. Dutra, D. Bürger, Compos. Part B: Eng. (2017). https://doi.org/10.1016/j.compositesb.2017.05. 013

9. A. Gupta, I. Fidan, S. Hasanov, A. Nasirov, Int. J. Adv. Manuf. Technol. (2020). https://doi.org/10.1007/s00170-020-05195-z

10. L.G. Blok, M.L. Longana, H. Yu, B.K.S. Woods, Addit. Manuf. (2018). https://doi.org/10.1016/j.addma.2018.04.039

11. L. Thijs, M.L. Montero Sistiaga, R. Wauthle, Q. Xie, J.-P. Kruth, J. Van Humbeeck, Acta Mater. (2013). https://doi.org/10.1016/j. actamat.2013.04.036

12. N.S. Hmeidat, R.C. Pack, S.J. Talley, R.B. Moore, B.G. Compton, Addit. Manuf. (2020). https://doi.org/10.1016/j.addma.2020. 101385

13. S. Ahn, M. Montero, D. Odell, S. Roundy, P.K. Wright, Rapid Prototyp. J. (2002). https://doi.org/10.1108/13552540210441166

14. N. van de Werken, J. Hurley, P. Khanbolouki, A.N. Sarvestani, A.Y. Tamijani, M. Tehrani, Compos. Part: B Eng. (2019). https:// doi.org/10.1016/j.compositesb.2018.12.094

15. S. Bhandari, R.A. Lopez-Anido, D.J. Gardner, Addit. Manuf. (2019). https://doi.org/10.1016/j.addma.2019.100922

16. W.M.H. Verbeeten, M. Lorenzo-Bañuelos, P.J. Arribas-Subiñas, Addit. Manuf. (2020). https://doi.org/10.1016/j.addma.2019. 100968

17. C. Casavola, A. Cazzato, V. Moramarco, G. Renna, Materials (2019). https://doi.org/10.3390/ma12081295
18. S.N. Aishah Majid, M.R. Alkahari, F.R. Ramli, S. Maidin, C.F. Tan, M.N. Sudin, J. Mech. E, pp. 185-197. ISSN 18235514 (2017)

19. M. Utzeri, M. Sasso, G. Chiappini, S. Lenci, J. Comput. Nonlinear Dyn. (2020). https://doi.org/10.1115/1.4048913

20. A. du Plessis, B.J. Olawuyi, W.P. Boshoff, Mater. Struct. (2016). https://doi.org/10.1617/s11527-014-0519-9

21. R. Othman (ed.), The Kolsky-Hopkinson Bar Machine: Selected Topics (Springer, Berlin, 2018). https://doi.org/10.1007/ 978-3-319-71919-1

22. W. Chen, B. Song, Split Hopkinson (Kolsky) Bar (Springer, Boston, 2011). https://doi.org/10.1007/978-1-4419-7982-7

23. E. Mancini, M. Sasso, M. Rossi, G. Chiappini, G. Newaz, D. Amodio, J. Dyn. Behav. Mater. (2015). https://doi.org/10.1007/ s40870-015-0019-1

24. M. Sasso, G. Newaz, D. Amodio, Mater. Sci. Eng., A (2008). https://doi.org/10.1016/j.msea.2007.10.042

25. G. Mirone, R. Barbagallo, D. Corallo, S. Di Bella, Procedia Struct. Integr. (2016). https://doi.org/10.1016/j.prostr.2016.06.295

26. E. Farotti, E. Mancini, T. Bellezze, M. Sasso, J. Dyn. Behav. Mater. (2019). https://doi.org/10.1007/s40870-019-00218-7

27. M. Sasso, M.G. Antonelli, E. Mancini, M. Radoni, D. Amodio, Int. J. Impact Eng (2017). https://doi.org/10.1016/j.ijimpeng. 2016.12.020

28. M. Sasso, A. Forcellese, M. Simoncini, D. Amodio, E. Mancini, Key Engineering Materials (Trans Tech Publications Ltd, Bäch, 2015)

29. B. Song, W. Chen, Exp. Mech. (2004). https://doi.org/10.1007/ bf02427897

30. T.P.M. Johnson, S.S. Sarva, S. Socrate, Exp. Mech. (2009). https:// doi.org/10.1007/s11340-009-9305-y

31. R. Gerlach, S.K. Sathianathan, C. Siviour, N. Petrinic, Int. J. Impact Eng (2011). https://doi.org/10.1016/j.ijimpeng.2011.08.007 